\title{
FORUM
}

\section{The Reliability of Sights at Sea}

\author{
from Commander J. M. Sharpey-Schafer, R.N.
}

THE note in the Forum 'The Accuracy of Astronomical Observations at Sea' by G. A. Harding (this Journal, Vol. VII, p. 195) and the paper 'The Barcoo Observations' by J. B. Parker and D. H. Sadler (this Journal, Vol. VII, p. 317) were interesting, but although some practical navigators have dabbled with the theory of errors one is apt to feel a little bit blinded by the science of the mathematicians on the subject of 'errors', when such things as 'constant bias', 'quasi systematic error', 'internal standard deviations', and a 'square root law' (p. 320, Table I, Col. 7) are bandied about. One hopes one knows what they mean, but there is a lurking doubt, though one might not admit it, and they do not quite seem to click with the sort of phrases taught to navigators.

If one looks at the articles again and again, one might well wonder from some of the evidence whether the sights are so very much better than a mile, although the mathematicians seem to suggest that in 'tone' they may be noticeably better. Do the observations they deal with quite compare with the occasion, rare as to weather, convenience and results, of a set of eleven sights whose intercepts were within three cables of the true position, quoted in 'Some Notes on Astronomical Observations at Sea' (this Journal, Vol. VI, p. 362); that article shows a 'tone' of accuracy of about a mile.

In discussions of radar fixing accuracy, and in methods of minesweeping, one may often hear scientists talking about r.m.s. (root mean square) probable error, and one learns that, say, 60 or 80 per cent lie inside that error and 40 or 20 per cent lie outside, which in so many cases is not very reliable, as shown below in two practical examples.

A narrow area limited by depth up to 200 miles from land in North Atlantic waters had been mined two years previously, using ordinary sights, some of which were said to be accurate to $\frac{1}{2}$ or $\frac{1}{4}$ mile, although the recorded plots of position lines showed larger cocked hats of 1 to 2 miles wide. The problem then came before the navigators of whether they were prepared to take the squadron of heavy minelayers within I or 2 miles of the old minefields (with some murky weather, D.R. runs and other difficulties, besides the accuracy of their own sights), or even the wing ship of its destroyer screen within $\frac{1}{2}$ mile. So far as is recollected the consensus of opinion was in the negative, and 5 miles with not less than 3 even if sights were average or good had to be accepted, even if it meant a lot of bother to other operational requirements.

Secondly, at the height of one of the mine threats in the last war, a certain port had lost three important tankers in as many days in a route specially swept; when the Chief of Staff received the excuse that the channel had been swept to 80 per cent he replied, 'Go and sweep to 300 per cent', and more mines were found.

Perhaps it boils down to this-that the mathematician's 'probable errors', \&c., seem to give a glow that is a little too rosy and optimistic, a sort of minimum circle within which a fairly large number of observations should lie. 'Constant bias' and 'quasi systematic errors' may seem all right, but it is not at all certain 
that all navigators are prepared to accept the assumptions on which they seem to be based, even if they are quite clear what the assumptions are. The practical navigator or operator so much more often requires 'reliability', a sort of magic circle within which all but about 3 per cent will lie; and for that 3 per cent criteria to show when a few rare ones are so grossly bad that they can obviously be neglected. He also needs to use it in a reasonable time of, say, $\frac{1}{4}$ to $\frac{1}{2}$ hour, without too heavy a battle with formulae and analysis.

One may feel that the subject is important, because in many walks there is quite a propaganda and education about it from the scientist to the sailor. Let the worm squirm a little and ask if the scientist realizes that quite a lot of other important things so often depend on 'errors'. To be constructive: what then can the mathematician offer the navigator in the way of a practical theory of reliability?

\section{Mr. D. H. Sadler comments :}

Everyone will welcome Commander Sharpey-Schafer's note on reliability, since it expresses admirably the difficulties of interpretation that inevitably arise between the practical navigator and the theoretical mathematician or statistician. There is a wide gap here which is difficult to bridge; it presents a challenge to the theorists who must somehow give guidance to the navigators in a form they can understand and use. It is precisely for this reason that the Institute's first monograph will be on the appreciation and understanding of errors.

In any particular set of circumstances it is possible to estimate the probability of any given error arising, or to state the error zone corresponding to any given probability. The larger the information available the better will be the estimate, but an estimate can always be given; if much data is available the estimate can be relied upon pretty accurately. But what the theory cannot do is to balance the risks which the navigator must run in accepting any given probability level. If there is, for.instance, a 0.1 per cent chance of an error exceeding 3 miles, and if such an error might put him inside a minefield, he is clearly not going to take that chance. But he would be stupid not to take that chance if the consequences of an error exceeding 3 miles were merely a minor inconvenience, or if there happened to be other factors contributing to uncertainty of which no estimate could be made.

This last point is important. When two or more independent sources of error exist, little is gained by going to much trouble to reduce a small error, as the larger error always dominates; and in astronomical navigation the actual errors of observation do appear to be quite large.

\section{Mr. J. B. Parker comments:}

Commander Sharpey-Schafer's interesting note raises two fundamental issues:

(I) What is the simplest and best way of expressing the error in a single position line?

(2) How, from a knowledge of this error, can the error of the resulting fix obtained from several similar position lines be estimated?

The first question presents no real difficulties, but a firm answer cannot be given since there is no magic zone in which the true position line must lie. For this reason the navigator and mathematician alike have to take refuge in a compromise percentage figure. What percentage figure to take depends on the navigator and on the occasion. For Commander Sharpey-Schafer's minelaying 
example, a 99.99 per cent figure might well be called for, but for ordinary navigation purposes this would result in such a wide band as to be useless.

The statistician is accustomed to talk in terms of the standard deviation. This corresponds to the 67 per cent error, which may seem rather artificial; but there are sound theoretical grounds for preferring it. In any case, if the navigator sometimes wants to make use of one probability level and sometimes another, it is clear that the knowledge of a single percentage figure is of little value. What the navigator might find useful is a working rule enabling him to convert from one percentage to another. A table to do this is given below; it gives the factor by which the standard deviation of a single position line must be multiplied in order to get the percentage error.

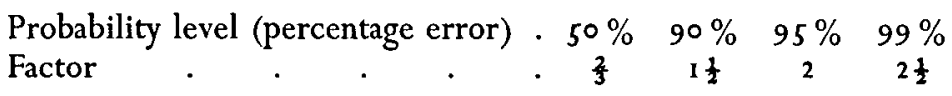

This is an easily remembered little table; thus the 95 per cent zone for a single position line is a band, the boundaries of which are two standard deviations away from the line. Using this, a good rough criterion for deciding whether a suspect position line should be ignored or not is to measure its distance from the fix obtained from the remaining position lines. If this is more than two standard deviations the position line should be thrown out. Using this criterion, and assuming a standard deviation of one nautical mile, two of Lt. Cdr. S.'s sights quoted by Commander Sharpey-Schafer in 'Some Notes on Astronomical Observations at Sea' (Fig. 1, Vol. VI, p. 365) would be disqualified. This seems reasonable.

The second question is difficult. The appropriate error circle for a fix depends not only on the number of position lines, but also on their distribution in azimuth. Without a good deal of theoretical investigation, one can only lay down the following rough-and-ready rules.

(I) For a two-line fix, with a $90^{\circ}$ angle of cut, the radius of the 50 per cent circle is $1 \cdot 2$ times the s.d. of the component position lines (alternatively $1 \cdot 75$ times the $5^{\circ}$ per cent error of the two position lines).

(2) The radius of the $5^{\circ}$ per cent (or, for that matter, any percentage figure) circle for an $n$-line fix, whose position lines are well distributed in azimuth, varies inversely as the square root of $n$. Thus a four-line fix has a radius of $\sqrt{ }(2 / 4)=0.7$ times that of a two-line fix, and an eight-line fix has a radius half that of a two-line fix. The law of diminishing returns enters with a vengeance, and improving accuracy by taking more and more position lines is a slow job. In particular, the chance of eleven sights, all with a ( 50 per cent) error of a mile, giving position lines within only three cables of the true position is very small indeed: it must have been a lucky break!

\section{Methods of Astronomical Navigation}

The following is an extract from a letter sent in with a series of observations made for the working party investigating the accuracy of astronomical navigation at sea.

I THINK the Institute is doing a grand job in this matter of getting to the bottom of what actually happens at sea. I give a personal 'shabash' to D. H. Sadler \& Co. for the new Abridged Nautical Almanac, and to S. M. Burton for the first- 